\title{
PRODUÇÃO DE MUDAS DE CAJUEIRO ANÃO-PRECOCE EM SUBSTRATOS DE RESÍDUOS ORGÂNICO
}

Evaldo Morais da Silva ${ }^{11}$, Mariana Casari Parreira², Susana Cristine Siebeichler ${ }^{3}$, Elonha Rodrigues dos Santos ${ }^{4}$, Clovis Maurílio Souza ${ }^{5}$, Francisco das Chagas Vidal Neto ${ }^{6}$, Gilson Araujo de Freitas ${ }^{7}$

\begin{abstract}
RESUMO - A cajucultura está sendo introduzida no estado do Tocantins, principalmente na região central e norte em função da adaptação climática. A busca conciliada de novos materiais genéticos, juntamente com novas tecnologias para a produção de mudas tem um papel importante na consolidação da cajucultura. Diante disso, objetivou-se com este trabalho buscar alternativas de fontes orgânicas de nutrientes como: terra preta, composto orgânico, pó de serragem, esterco bovino, pó de casca de coco e casca de arroz carbonizada - para produção de substratos para mudas de cajueiro anão-precoce, nas condições de viveiro, no estado do Tocantins. No experimento foram utilizadas sementes do cajueiro anão precoce do clone CCP06, provenientes da Embrapa Agroindústria Tropical. O delineamento utilizado foi de blocos inteiramente casualizados com quatro repetições. Os substratos utilizados no experimento foram: (S1) terra preta + areia, (S2) terra preta + areia + composto orgânico, (T3) terra preta + areia + pó de serragem, (S4) terra preta + areia + esterco bovino, (S5) terra preta + areia + pó de casca de coco, (S6) terra preta + areia + casca de arroz carbonizada. Aos 60 dias após o plantio, foram avaliadas as variáveis altura de muda, diâmetro de colo, número de folhas, área foliar, comprimento de raiz, volume de raiz, massa seca das folhas, massa seca do caule, massa seca das raízes e massa seca total Os substratos contendo: terra preta + areia + composto orgânico e terra preta + areia + esterco bovino proporcionaram melhor crescimento das mudas de caju anão precoce clone CCP06 em condição de viveiro em Tocantins.
\end{abstract}

Palavras chave: Anacardium occidentale, crescimento inicial, mudas.

\section{PRODUCTION OF SEEDLINGS OF EARLY DWARF CASHEW IN ORGANIC WASTE SUBSTRATES}

\begin{abstract}
The cashew crop is being introduced in the State of Tocantins, mainly in central and North because climate adaptation function. The reconciled search for new genetic materials along with new technologies for seedling production plays an important role in the consolidation of cashew in this State. So, the objective of this work seek alternatives to organic sources of nutrients like: black soil, substrate organic compound, sawdust, cow manure, coconut shell powder and carbonized rice husk-for production of substrates for seedlings of early dwarf cashew, nursery conditions, in the State of Tocantins. In the experiment were used seeds of dwarf cashew early CCP06, from Embrapa Tropical. A completely randomized block design with four replications was used. Black soil + sand + Sodium + sand + organic compound, (T3) black soil + sand + sawdust powder, (S4) black soil + sand + bovine manure, (S5) black soil + sand + coconut shell powder, (S6) black soil + sand + carbonized rice husk. At 60 days after planting, the following variables were evaluated: seed height, leaf diameter, leaf number, leaf area, root length, root volume, leaf dry mass, stem dry mass, root dry mass and mass dry soil. The substrates containing: black soil + sand + organic compound and black soil + sand + bovine manure provided better growth of the early dwarf cashew seedlings CCP06 in nursery condition in Tocantins.
\end{abstract}

Keywords: Anacardium occidentale, initial growth, root stock production.

\footnotetext{
${ }^{1}$ evaldomorais@ufpa.br.

${ }^{2}$ mcparreira@ufpa.br: Campus Universitário do Tocantins (CUNTINS)-Universidade Federal do Pará (UFPA).

${ }^{3}$ susana@mail.uft.edu.br: Universidade Federal do Tocantins (UFT).

${ }^{4}$ elonharodrigues@gmail.com: FAMA-Faculdade da Amazônia.

${ }^{5}$ clovis@uft.edu.br: Universidade Federal do Tocantins (UFT).

${ }^{6}$ vidal@cnpat.embrapa.br: Embrapa Agroindústria Tropical; araujoagro@hotmail.com: Universidade Federal do Tocantins (UFT).
} 


\section{INTRODUÇÃO}

O cajueiro (Anacardium occidentale L.) é constituído por árvores ou arbustos que apresentam ductos resiníferos em seus ramos, seus frutos "pseudofrutos" apresentam sabor agradável, possui a núcula como fruto verdadeiro, conhecido como “castanha-de-caju”, plantas produtoras de boa madeira ou de substâncias usadas na indústria e na medicina (Barroso, 1999; Barroso, 1999). No semiárido do nordeste, seu cultivo representa uma das principais fontes de geração de emprego e renda dos agricultores. A expansão da cajucultura está apoiada na utilização de clones de cajueiro anão-precoce (Serrano et al., 2013; Araújo et al., 2014). No Tocantins, nos últimos anos, o governo estadual vem fomentando a produção dessa cultura. Em 2017, foi registrada uma colheita de 149,3 $t$ de frutos e 23,6 t de castanha, tendo como principais produtores os municípios de Palmas e Nova Olinda, respectivamente (IBGE, 2017).

O potencial de sobrevivência das plantas no campo depende entre outros fatores da qualidade das mudas usadas no plantio. Segundo Frade Junior et al. (2011) a produção de mudas constitui uma das etapas mais importantes do sistema produtivo, sendo altamente dependente da utilização de insumos.

A procura por materiais alternativos para a composição de substratos orgânicos na produção de mudas é contínua, visto que, os resíduos têm que ser abundantes, de baixo custo e provenientes da reciclagem, pois além de condicionar a produção de mudas contribui com a preservação do meio ambiente (Freitas et al., 2013).

Dentre os possíveis componentes para formação de um substrato para plantas está a casca de arroz carbonizada, resíduo de difícil decomposição que é descartado em grande volume no ambiente (Souza, 1993). No ano agrícola 2016/17, no Brasil, foram colhidas 12.327,8 mil toneladas de arroz (CONAB, 2018) sendo geradas aproximadamente 2.465,5 mil toneladas de casca. Segundo Saidelles et al. (2009) essa casca de arroz quando carbonizada pode ser utilizada como componente em substratos, por permitir a penetração e a troca de ar na base das raízes.

Outro resíduo de grande importância no Tocantins é o resíduo das indústrias frigoríficas. No quarto trimestre de 2015 foram abatidos 230 mil animais (IBGE, 2016), gerando grande volume de resíduos o qual necessita ser empregado de forma sustentável. Estes resíduos estão sendo utilizados na formação de um composto orgânico para a produção de mudas.

A qualidade das mudas além do material genético depende, também, dos tratos culturais empregados na sua produção, os quais deverão ter o menor custo de produção para que não onere o preço da muda comercializada. Assim, o uso da casca de arroz, esterco bovino curtido e resíduos de frigorífico são produtos alternativos que poderão ser utilizados na fabricação de substratos orgânicos para produção de mudas. Possivelmente, substratos que utilizam resíduos de frigorifico em sua constituição poderão produzir mudas mais vigorosas ideais para produtores e viveiristas que almejam menor custo de produção, muda de boa qualidade e menor tempo no viveiro, além de ser um sistema sustentável.

Diante disso, objetivou-se com este trabalho buscar alternativas de fontes orgânicas de nutrientes como: terra preta, composto orgânico, pó de serragem, esterco bovino curtido, pó de casca de coco e casca de arroz carbonizada - para produção de substratos para mudas de cajueiro anão-precoce, nas condições de viveiro, no estado do Tocantins.

\section{MATERIALE MÉTODOS}

O experimento foi conduzido no período de janeiro a março de 2011 em telado com sombrite (50\% de luminosidade) na área experimental do Campus Universitário de Gurupi, da Universidade Federal do Tocantins, na cidade de Gurupi-TO localizado a 280 m de altitude, $11^{\circ} 43^{\prime} \mathrm{S}$ e $49^{\circ} 04^{\prime} \mathrm{W}$. De acordo com a classificação climática de Thornthwaite, o clima na região em estudo é C2 wA'a"', caracterizado como úmido subúmido e de moderada deficiência hídrica no inverno (SEPLAN, 2012). No experimento foram utilizadas sementes do cajueiro anão-precoce do clone CCP06, proveniente da Embrapa Agroindústria Tropical.

O experimento foi conduzido em delineamento de blocos casualizados com seis tratamentos e quatro repetições, totalizando 24 unidades experimentais. Os tratamentos consistiram de substratos utilizados para a produção de mudas: (S1) terra preta+areia, na proporção 2:1, (S2) terra preta+areia+composto orgânico, (S3) terra preta+areia+pó de serragem, (S4) terra preta+areia+esterco bovino curtido, (S5) terra 
preta+areia+pó de casca de coco e (S6) terra preta+areia+casca de arroz carbonizada, todos estes na proporção 2:1:1.

O composto orgânico utilizado é proveniente do processo de compostagem através da mistura de conteúdo ruminal bovino enriquecido com farinha de carne e osso.

Após a realização das misturas para o preparo dos substratos retirou-se uma amostra de cada tratamento para a caracterização química. Os resultados encontramse dispostos na Tabela 1.

As sementes foram semeadas em sacos de polietileno de 2 L de volume, sendo colocada uma semente por saco. A irrigação foi feita diariamente para manter o substrato próximo da capacidade de campo. A emergência foi observada todos os dias até o aparecimento da última plântula. A porcentagem final de emergência foi determinada aos 30 dias após a semeadura, quando, após uma semana, nenhuma plântula emergiu.

O índice de velocidade de emergência (IVE) foi calculado pelo somatório das razões do número de plantas emergidas no período, pelo número de dias da semeadura à emergência, usando-se a fórmula proposta por Maguire (1962).

Aos 60 dias após a emergência (DAE) foram determinados altura das plantas, diâmetro do caule e o número de folhas por planta. A altura foi determinada a partir do colo da planta até o meristema apical, com o uso de uma régua graduada em centímetros $(\mathrm{cm})$; o diâmetro do caule foi mensurado a cinco cm do nível do substrato, utilizando um paquímetro digital e os resultados expressos em ( $\mathrm{mm})$. Ainda no viveiro, as mudas tiveram seu caule cortado rente ao solo e a parte aérea seccionada em folhas e caules e encaminhadas para o laboratório de Ecofisiologia Vegetal da UFT - Campus Gurupi.

No laboratório, foram retirados 15 discos de $7 \mathrm{~mm}$ de diâmetro para determinação da área foliar, segundo o método dos discos que consiste da secagem dos discos separadamente do resto das folhas. Após a obtenção da massa seca foi calculado a área pela massa seca total das folhas por regra de três (BENINCASA, 2003):

Massa seca dos discos ---- área total dos discos $\left(\mathrm{cm}^{2}\right)$

Massa seca total das folhas ---- X $\left(\mathrm{cm}^{2}\right)$

O comprimento da maior raiz foi medido com o auxílio de régua milimétrica. Após estes procedimentos, todo material (discos, folhas, caules e sistema radicular) foi levado à estufa de circulação de ar forçada a $65^{\circ} \mathrm{C}$, para secagem até peso constante, em uma balança semianalítica, com exceção dos discos que foram mensurados em balança analítica. A determinação da massa seca total (MST) foi pela soma das massas da parte aérea (MSPA) e raízes (MSR).

Para obtenção do Índice de Qualidade de Dickson (IQD) foi utilizada a metodologia proposta por Dickson et al. (1960), considerando as variáveis morfológicas das mudas e suas relações, utilizadas nas avaliações dos resultados.

Tabela 1 - Características químicas dos substratos utilizados para produção de mudas de cajueiro anão precoce

\begin{tabular}{|c|c|c|c|c|c|c|}
\hline Característica & $\mathrm{S} 1$ & S2 & S3 & S4 & S5 & S6 \\
\hline $\mathrm{Ca}+\mathrm{Mg}$ (cmolc.dm-3) & 3,31 & 5,54 & 2,98 & 3,44 & 2,95 & 1,00 \\
\hline Ca (cmolc.dm-3) & 3,04 & 5,21 & 2,89 & 2,84 & 1,32 & 0,91 \\
\hline Mg (cmolc.dm-3) & 0,27 & 0,33 & 0,09 & 0,60 & 1,63 & 0,09 \\
\hline $\mathrm{Al}$ (cmolc.dm-3) & 0,00 & 0,00 & 0,00 & 0,00 & 0,00 & 0,00 \\
\hline $\mathrm{H}+\mathrm{Al}$ (cmolc.dm-3) & 2,05 & 2,28 & 2,13 & 1,72 & 2,04 & 1,17 \\
\hline K (cmolc.dm-3) & 0,84 & 0,61 & 0,61 & 0,61 & 0,66 & 0,84 \\
\hline CTC(T) (cmol.dm-3) & 6,20 & 8,43 & 5,72 & 5,77 & 5,64 & 3,01 \\
\hline SB (cmolc.dm-3) & 4,15 & 6,15 & 3,59 & 4,05 & 3,61 & 1,84 \\
\hline P (mg.dm-3) & 16,00 & 57,00 & 16,00 & 26,00 & 41,00 & 31,00 \\
\hline $\mathrm{V}(\%)$ & 66,98 & 72,98 & 62,78 & 70,24 & 63,89 & 61,09 \\
\hline M.O (\%) & 2,47 & 4,68 & 3,34 & 2,61 & 0,99 & 2,11 \\
\hline $\mathrm{pH}(\mathrm{H} 2 \mathrm{O})$ & 6,36 & 5,63 & 6,59 & 5,89 & 5,62 & 6,57 \\
\hline
\end{tabular}

S1: terra preta + areia, S2: terra preta + areia + composto orgânico, S3: terra preta + areia + pó de serragem, S4: terra preta + areia + esterco bovino, S5: terra preta + areia + pó de casca de coco e S6: terra preta + areia + casca de arroz carbonizada. Análise realizada no laboratório de solos no Campus de Gurupi da Universidade Federal do Tocantins. 


$$
I Q D=\frac{M S T(\mathrm{~g})}{\frac{H(\mathrm{~cm})}{D C(\mathrm{~cm})}+\frac{\operatorname{MSPA}(\mathrm{g})}{\operatorname{MSRA}(\mathrm{g})}}
$$

Em que:

IQD - Índice de Qualidade de Dickson, MST - Massa seca total (g), H - altura (cm), DC - diâmetro do caule (cm), MSPA - Massa seca da parte aérea (g) e MSRA - Massa seca da raiz (g).

Os dados obtidos foram submetidos à análise de variância e, quando significativo, as médias foram comparadas pelo teste de Tukey a Pd”0,05, utilizandose o programa estatístico Sistema para Análise de Variância - SISVAR (FERREIRA, 2011).

\section{RESULTADOS E DISCUSSÃO}

Os substratos não influenciaram no índice de velocidade de emergência e na porcentagem de emergência das plântulas de cajueiro anão-precoce CCP 06 (Tabela 2).

A massa seca das folhas e do caule, massa seca total, diâmetro do caule e o número de folhas não foram influenciados pelo substrato (Tabela 3 e 4). A massa seca da raiz apresentou diferença significativa entre os substratos, onde o substrato composto por terra preta+areia (S1) promoveu maior massa seca da raiz, mas não diferindo dos substratos com composto orgânico (S2), esterco (S4) e casca de arroz carbonizada (S6) (Tabela 3).

Os substratos com pó de serragem (S3) e com pó da casca do coco (S5) apresentaram os menores valores para MSR (Tabela 3). Correia et al. (2005) trabalhando

Tabela 2 - Índice de velocidade de emergência (IVE), porcentagem de emergência (PE), de mudas de cajueiro anão precoce clone CCP 06

\begin{tabular}{lcc}
\hline Substratos & IVE $^{\mathrm{ns}}$ & PE $(\%)^{\mathrm{ns}}$ \\
\hline S1: Terra preta+areia & 0,45 & 100,00 \\
S2: Terra preta+areia+composto orgânico & 0,47 & 97,00 \\
S3: Terra preta +areia+pó serragem & 0,44 & 97,00 \\
S4: Terra preta+ areia+esterco bovino & 0,45 & 97,00 \\
S5: Terra preta+areia+pó casca coco & 0,44 & 93,75 \\
S6: Terra preta+areia+casca arroz carb. & 0,48 & 100,00 \\
CV(\%) & 5,44 & 6,06 \\
\hline
\end{tabular}

ns: não significativo pelo teste de Tukey, a $\mathrm{P}<0,05$. com produção de mudas de goiabeira, observaram um menor crescimento radicular no substrato que continha casca de coco e folha de carnaubeira triturada. No presente estudo pode-se considerar que a baixa disponibilidade de matéria orgânica (Tabela 1), possivelmente, tenha influenciado negativamente no crescimento radicular em função da competição com os microrganismos pelo nitrogênio existente no substrato.

O comprimento das mudas nos substratos contendo composto orgânico (S2), esterco bovino (S4) e casca de arroz carbonizada (S6) não difere entre si e no geral apresentam os melhores valores. O uso de esterco bovino na composição do substrato também foi recomendado para a produção de mudas em sacos de polietileno para mangabeira (Silva et al., 2009). O uso de compostos orgânicos provenientes de resíduos de frigorífico foi recomendado para a produção de mudas de alface por Freitas, et al. (2013).

O substrato contendo casca de coco (S5) apresentou o menor comprimento radicular (comprimento de raiz). Segundo Kampf \& Fermino (2000), o substrato contendo pó de casca de coco pode ter alto teor de taninos solúveis, os quais, quando concentrados, são fitotóxicos e inibem o crescimento das raízes. Provavelmente, esta tenha sido a razão do menor crescimento radicular de caju anão precoce neste substrato.

O substrato que apresentou maior área foliar (Tabela 4) e relação altura/diâmetro de caule (Tabela 5) foi o que continha esterco bovino curtido diferindo significativamente somente do substrato com pó de serragem. Em parte, o aumento da área foliar pode ter sido influenciado pelo número de folhas, que não diferiu entre os tratamentos, mas as mudas produzidas no substrato com esterco bovino apresentaram uma folha a mais em relação aos demais substratos.

Os menores valores de área foliar, altura da muda e relação altura/diâmetro de caule foram obtidos no substrato com pó de serragem (S3) (Tabelas 4 e 5). Resultado semelhante foi encontrado em mamoeiro (COSTA et al, 2010) e em maracujazeiro (COSTA et al., 2009). Em ambos os trabalhos é afirmado que a maior porcentagem de pó de serragem condicionou o menor desenvolvimento de muda, sugerindo que o processo de estabilização do substrato demanda tempo e suprimento de nutrientes extra, principalmente nitrogênio, causando uma competição entre os microrganismos do solo e a muda pelo nitrogênio disponível no substrato. 
Tabela 3 - Massa seca das folhas (MSF), massa seca das raízes (MSR), massa seca do caule (MSC), massa seca total (MST) de mudas de cajueiro anão precoce clone CCP 06, aos 60 dias após a semeadura

\begin{tabular}{|c|c|c|c|c|}
\hline Substratos & MSF ns & MSR & MSC ns & MST ns $^{\text {ns }}$ \\
\hline & & & & \\
\hline S1-Terra preta+areia & 1,81 & 1,81 a & 1,32 & 5,00 \\
\hline S2-Terra preta+areia+composto orgânico & 2,00 & $1,49 \mathrm{ab}$ & 1,34 & 4,81 \\
\hline S3-Terra preta +areia+pó serragem & 1,60 & $1,32 \mathrm{~b}$ & 1,29 & 4,43 \\
\hline S4-Terra preta + areia+esterco bovino & 2,12 & $1,50 \mathrm{ab}$ & 1,29 & 5,12 \\
\hline S5-Terra preta+areia+pó casca coco & 1,81 & $1,30 \mathrm{~b}$ & 1,33 & 4,56 \\
\hline S6-Terra preta+areia+casca arroz carb. & 2,00 & $1,75 \mathrm{ab}$ & 1,44 & 5,37 \\
\hline CV(\%) & 28,30 & 31,04 & 29,41 & 21,02 \\
\hline
\end{tabular}

ns: não diferem entre si, significativo pelo teste de Tukey, a 5\% de probabilidade. Médias seguidas de letras iguais na coluna não diferem entre si, pelo teste de Tukey, a $\mathrm{P}<0,05$.

Tabela 4 - Comprimento da raiz (CR), altura da muda (AM), diâmetro do caule (DC), número de folhas (NF) e área foliar (AF) de mudas de cajueiro anão precoce 60 dias após a semeadura

\begin{tabular}{|c|c|c|c|c|c|}
\hline Substratos & $\mathrm{CR}(\mathrm{cm})$ & $\mathrm{AM}(\mathrm{cm})$ & $\mathrm{DC}(\mathrm{mm}) \mathrm{ns}$ & NFns & $\operatorname{AF}\left(\mathrm{cm}^{2}\right)$ \\
\hline S1-Terra preta+areia & $32,18 \mathrm{ab}$ & 24,06 bc & 5,26 & 10,37 & $178 \mathrm{ab}$ \\
\hline S2-Terra p.+areia+comp. orgânico & 36,68 a & $25,76 \mathrm{ab}$ & 5,31 & 10,56 & $206 \mathrm{ab}$ \\
\hline S3-Terra p. +areia+pó serragem & $33,87 \mathrm{ab}$ & $22,59 \mathrm{c}$ & 5,15 & 10,37 & $176 \mathrm{~b}$ \\
\hline S4-Terra p.+ areia+esterco bovino & $33,81 \mathrm{ab}$ & 28,37 a & 4,99 & 11,31 & 224 a \\
\hline S5-Terra p.+areia+pó casca coco & $30,31 \mathrm{~b}$ & 27,12 ab & 5,26 & 10,62 & $183 \mathrm{ab}$ \\
\hline S6-Terra p.+areia+casca arroz carb. & $33,50 \mathrm{ab}$ & 28,56 a & 5,27 & 11,06 & $197 \mathrm{ab}$ \\
\hline $\mathrm{CV}(\%)$ & 15,16 & 11,62 & 9,32 & 13,88 & 22,89 \\
\hline
\end{tabular}

ns: não diferem entre si, significativo pelo teste de Tukey, a 5\% de probabilidade. Médias seguidas de letras iguais na coluna não diferem entre si, pelo teste de Tukey, a $\mathrm{P}<0,05$.

Tabela 5 - Teste de médias das relações atribuídas à qualidade de mudas, relação altura e diâmetro do caule (RH/DC), relação da massa seca da parte aérea e massa seca das raízes (RPA/R), índice de qualidade de Dickson (IQD) de mudas de cajueiro anão precoce CCP06 em função dos substratos

\begin{tabular}{lccc}
\hline Substratos & RH/DC & RPA/R & IQDns \\
\hline S1-Terra preta+areia & $4,64 \mathrm{~cd}$ & $1,04 \mathrm{c}$ & 0,89 \\
S2-Terra preta+ composto orgânico & $4,90 \mathrm{bcd}$ & $1,38 \mathrm{ab}$ & 0,76 \\
S3-Terra preta +areia+pó serragem & $4,43 \mathrm{~d}$ & $1,42 \mathrm{ab}$ & 0,76 \\
S4-Terra preta+ areia+esterco bovino & $5,69 \mathrm{a}$ & $1,50 \mathrm{a}$ & 0,71 \\
S5-Terra preta+areia+pó casca coco & $5,16 \mathrm{abc}$ & $1,34 \mathrm{ab}$ & 0,70 \\
S6-Terra preta+areia+casca arroz carbonizada & $5,42 \mathrm{ab}$ & $1,20 \mathrm{bc}$ & 0,81 \\
CV $(\%)$ & 13,20 & 21,85 & 29,05 \\
\hline
\end{tabular}

ns: não diferem entre si, significativo pelo teste de Tukey, a 5\% de probabilidade. Médias seguidas de letras iguais na coluna não diferem entre si, pelo teste de Tukey, a $\mathrm{P}<0,05$.

Para a relação entre a massa seca da parte aérea e a massa seca da raiz, o substrato com esterco bovino (Tabela 5) apresentou o maior valor e diferiu significativamente dos substratos contendo casca de arroz carbonizada e do substrato com terra preta+areia que apresentou o menor valor.
As relações altura/diâmetro do caule e parte aérea/ raiz são úteis para avaliar a qualidade da muda ao compará-las com os dados originais coletados, podendo se constatar que o substrato contendo esterco bovino curtido, composto orgânico e casca de arroz carbonizada são boas opções de substratos (Tabelas 3, 4 e 5). 
McNabb (1985) e Boyer \& South (1987) constataram que as altas relações de peso das partes aérea/radicular indicam pequena superfície de absorção quando comparadas com a superfície de transpiração, o que afeta a resistência das mudas às condições de seca. No entanto, no presente trabalho o substrato que condicionou essa maior relação (Tabela 5) foi o que proporcionou melhor desenvolvimento de muda (Tabela 4), demonstrando que esta é uma muda mais vigorosa. Segundo Gomes \& Paiva (2004), a massa seca da parte aérea indica a rusticidade e correlaciona-se diretamente com a sobrevivência e desempenho inicial das mudas após o plantio no campo.

O índice de qualidade de Dikson é considerado uma medida morfológica integrada. Para este não foi observada diferença entre os substratos (Tabela 5). A interpretação deste índice é: quanto maior o índice, melhor os resultados, assim uma muda ideal deve apresentar porte baixo, colo grosso, menos folhas e mais raízes (Dikson et al., 1960).

O substrato formado por areia e terra preta (S1), nesta condição não pode ser desconsiderado, pois concluise que a qualidade deste substrato não foi inferior aos demais testados, sendo que na maioria das variáveis avaliadas o mesmo não difere estatisticamente dos melhores resultados (Tabelas 1 a 5).

Dentre todos os substratos avaliados os formulados com esterco bovino curtido (S4), ou composto orgânico (S2) ou casca de arroz carbonizada (S6) produziram mudas de qualidade satisfatória. Em função da disponibilidade destes substratos no estado do Tocantins sugere-se, para redução dos custos de produção das mudas, a utilização destes substratos.

\section{CONCLUSÕES}

Os substratos contendo: terra preta + areia + composto orgânico e terra preta + areia + esterco bovino curtido proporcionaram melhor crescimento das mudas de caju anão precoce clone CCP06 em condição de viveiro em Tocantins.

\section{LITERATURA CITADA}

ARAÚJO, L.F.; LIMA, R.E.M.; COSTA, L.O. et al. Alocação de íons e crescimento de plantas de cajueiro anão-precoce irrigadas com água salina no campo. Revista Brasileira de Engenharia Agrícola e Ambiental, v.18, p.34-38. <https://dx.doi.org/ 10.1590/1807-1929/agriambi.v18nsupps34-s38>
BARROSO, G.M. Sistemática de angiospermas do Brasil. Viçosa, MG: Universidade Federal de Viçosa, 1991. v.2. 377p.

BARROSO, G.M. et al. Frutos e sementes: morfologia aplicada à sistemática de dicotiledôneas. Viçosa, MG: Universidade Federal de Viçosa, 1999. 443p.

BENINCASA, M.M.P. Análise de crescimento de plantas (Noções Básicas). Jaboticabal: FUNEP, 2003. 41p.

BOYER, J.N.; SOUTH, D.B. Excessive seedling height, high shoot-top-root ratio and benommy root dip reduce surviral of stored loblolly pine seedling. Tree Planters' Notes, v.38, n.4, p.19-22, 1987.

BRUNETTA, J.M.F.C.; ALFENAS, A.C.; MAFIA, R.G. et al. Crescimento de mudas de mamoeiro conduzidas em diferentes ambientes protegidos, recipientes e substratos na região de Aquidauana, Estado do Mato Grosso do Sul. Acta Scientiarum Agronomy, v.32, n.3, p.463-470, 2010.

CONAB - Companhia Nacional de Abastecimento. Acompanhamento da Safra Brasileira De Grãos: Safra 2017/18 - Sétimo Levantamento. V. 7, ISSN 2318-6852 Brasília, p. 1-139 abril 2018.

CORREIA, D.; RIBEIRO, E.M.; LOPES, L.S. et al. Efeito de substratos na formação de portaenxertos de psidium guajava l. cv. ogawa em tubetes. Revista Brasileira de

Fruticultura, v. 27, n. 1, p. 88-91, 2005.

COSTA, E.; LEAL, P.A.M.; SANTOS, L.C.R. dos et al. Crescimento de mudas de mamoeiro conduzidas em diferentes ambientes protegidos, recipientes e substratos na região de Aquidauana, Estado do Mato Grosso do Sul. Acta Scientiarum. Agronomy, v.32, n.3, p.463-470, 2010.

COSTA, E.; RODRIGUES, E.T.; ALVES, V.B. et al. Efeitos da ambiência, recipientes e substratos no desenvolvimento de mudas de maracujazeiroamarelo em Aquidauana. Revista Brasileira de Fruticultura, v.31, n.1, p.236-244, 2009. 
DICKSON, A.; LEAF, A.L.; HOSNER, J.F. Quality appraisal of white spruce and white pine seedling stock in nurseries. The Forestry.

Chronicle, v.36, p.10-13, 1960.

FERREIRA, D.F. SISVAR: a computer statistical analysis system. Ciência e Agrotecnologia, v.35, n.6, p.1039-1042, 2011.

FREITAS, G.A.; BARROS, H.B.; SANTOS, M.M. et al. Production of lettuce seedlings under different substrates and proportions of rice hulls.

Journal of Biotechnology and Biodiversity, v.4, n.3, p.260-268, 2013.

GOMES, J.M.; PAIVA, H.N. Viveiros florestais propagação sexuada. Viçosa: UFV, 2004. 116p.

HUNT, G.A. Effect of styroblock design and copper treatment on morphology of conifer seedlings. In:

ROSE, R.; CAMPBELL, S.J.; LANDIS, T.D. Target seedling symposium, meeting of the western forest nursery associations, general technical report rm-200. Roseburg: Forest Service, 1990. p.218-222.

Instituto Brasileiro de Geografia e Estatística IBGE. Levantamento Sistemático da Produção Agrícola, v. 29, n.7, p.1-87, 2016.

IBGE. Instituto Brasileiro de Geografia e Estatística. Disponível em: censoagro2017.ibge.gov.br/templates/censo_agro/ resultadosagro/agricultura.html

?localidade $=17 \&$ tema $=76263$. Acesso em: abril de 2017.

FRADE JUNIOR, E.F.; ARAÚJO, J.A.; SILVA, S.B. et al. Substratos de resíduos orgânicos para produção de mudas de Ingazeiro (Inga edulis) no vale do Juruá. Centro Científico Conhecer, v.7, n.13, p. 959-969, 2011.
KÄMPF, A.N.; FERMINO, M.H. Substratos para plantas: a base da produção vegetal em recipientes. In: encontro nacional sobre substrato para plantas, Porto Alegre, 2000. p.312.

MAGUIRE, J.D. Speed of germination-aid in selection and evaluation for seedling emergence and vigor. Crop Science, v.2, n.1, p.176-177, 1962.

MCNABB, K.L. The relationship of carbohydrate reserves to the quality of bare-root Pinuselliottii varelliotti (Engeln.). Tese (Doutorado em seedling produced in northern Florida Nursery. Florida: Florida University, 1985. 145p.

SAIDELLES, F.L.F.; CALDEIRA, M.V.W.; SCHIRMER, W.N. et al. Casca de arroz carbonizada como substrato para produção de mudas de tamboril-da-mata e garapeira.

Ciências Agrárias, v.30, p.1173-1186, 2009.

SERRANO, L.A.L.; MELO, D.S; TANIGUCHI, C.A.K. et al. Porta-enxertos para produção de mudas de cajueiro. Pesquisa Agropecuária brasileira, v.48, n.9, p.1237-1245, 2013.

SILVA, E.A.; MARUYAMA, W.I.; OLIVEIRA, A.C. de et al. Efeito de diferentes substratos na produção de mudas de mangabeira (Hancornia speciosa). Revista Brasileira

Fruticultura, v.31, n.3, p.925-929, 2009.

SOUZA, F.X. Casca de arroz carbonizada: um substrato para a propagação de plantas.

Revista Lavoura Arrozeira, v.46, n.406, p.11, 1993.

Recebido para publicação em 8/1/2019 e aprovado em 26/3/2019. 